\title{
The Mass Unit Disseminated to Surrogate Laboratories Using the NIST Portable Mass Calibration Package
}

Randall M. Schoonover James Taylor Joe Rothleder

U.S. DEPARTMENT OF COMMERCE Technology Administration National Institute of Standards and Technology

Gaithersburg, MD 20899

$-Q C$ 



\title{
The Mass Unit Disseminated to Surrogate Laboratories Using the NIST Portable Mass Calibration Package
}

\author{
Randall M. Schoonover \\ James Taylor \\ Joe Rothleder
}

U.S. DEPARTMENT OF COMMERCE Technology Administration National Institute of Standards and Technology

Gaithersburg, MD 20899

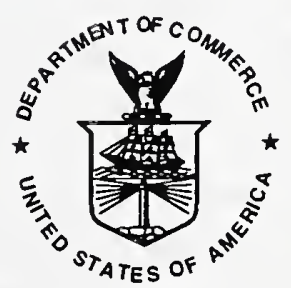

U.S. DEPARTMENT OF COMMERCE Ronald H. Brown, Secretary

TECHNOLOGY ADMINISTRATION

Mary L. Good, Under Secretary for Technology

NATIONAL INSTITUTE OF STANDARDS

AND TECHNOLOGY

Aratl Prabhakar, DIrector 



\title{
The Mass Unit Disseminated to Surrogate Laboratories using the NIST Portable Mass Calibration Package
}

\author{
Randall M. Schoonover, NIST \\ Gaithersburg, MD \\ James Taylor, NIST-Retired \\ Joe Rothleder, California State Metrologist
}

\begin{abstract}
Over a ten-year period, three mass calibration packages were circulated to selected laboratories by the Mass Group at NIST. Initially the objective was to determine if the NIST mass calibration service could be disseminated to qualified users via a "do-it-yourself" package. However, it became obvious that the technique could be very useful in the training of personnel and the examination of laboratories. The first package of 1-kilogram artifacts was circulated to see what problems might arise in their calibration. The second package was designed to overcome the difficulties encountered and to ensure the quality of the next package. The third and final package incorporates improvements and demonstrates the method with the calibration of the California State primary mass standards from $1 \mathrm{~kg}$ to $1 \mathrm{mg}$. This report looks briefly at the entire project experience with comments about the pitfalls and benefits of calibrations by surrogate laboratories and other likely uses of the method.
\end{abstract}

KEY WORDS: Mass, Calibration, Weight-Sets, Uncertainty

\section{INTRODUCTION}

The project began some years ago [1] with the premise that a NIST- certified calibration could be performed by the user in the users laboratory. With this goal in mind, a very informal low budget project was undertaken in order to expose the technical difficulties that lay in the way. Here we briefly touch the highlights of the earlier work $[2,3]$ and present data from the third package, with discussion, that we believe adequately demonstrates the successful achievement of our initial goal. Most importantly, in conclusion we discuss what we believe are the benefits and weaknesses of the original premise and comment on other possible uses of the method.

Initially the project looked primarily at the mass assignment to 1 kilogram artifacts in the participant laboratories. The results of earlier demonstrations [4] indicate that this would not be a problem for ordinary 1-piece laboratory weights made of stainless steel with densities of about $8 \mathrm{~g} / \mathrm{cm}^{3}$. 
However, these demonstrations exposed difficulties when large buoyant forces are encountered, as in the comparison of kilograms with large volume differences i.e., aluminum, stainless steel, tantalum and platinum as well as problems related to surface-dependent thermal effects and thermal inertia. Other work undertaken by NIST [5] and since verified by others [6] suggests, that the lack of thermal equilibrium during the measurements can present a serious obstacle in this undertaking; not necessarily with the comparison of identical single artifacts but for the aggregates that occur in combinational weighing. Unfortunately, surface-dependent thermal effects are not readily separable from the large buoyant effects mentioned above. After completing the initial round-robin, it was obvious that some of the participants needed assistance with the data reduction and nearly all of them lacked adequate accuracy in the pressure measurement, without which one cannot make reliable buoyancy corrections. In addition, taking into account the effects of temperature and humidity would require additional support. In essence we decided to supply the participants with a computer, software, thermometer, barometer, humidity sensor, mass standards, documentation and other items as part of the calibration package. The participant was required to provide a laboratory, the mass comparator and a skilled operator.

We believed that this was the a realistic approach to overcome apparent inadequacies in the participant laboratories' equipment and staff experience. With support for the project very limited and the pressure of other duties, we chose the California State laboratory as the only participant, besides ourselves, in phase 3 . Our choice was based on the technical support and our certainty that a strong astute critical review of the project would be forthcoming from California. Early on we realized this approach to calibration would also be useful in a rigorous examination of mass laboratories, and for the training of their staff. These last two issues are addressed in the discussion section of this report.

\section{REVIEW}

The first round-robin contained a normal 1-piece laboratory kilogram weight and the special 1-kg artifacts with exaggerated surfaces and volumes. Additionally, the package supplied a description of the required measurements and an appropriate data reduction algorithm. The results of these measurements were disappointing, especially when judged in terms of our experience with the mass Measurement Assurance Program (MAP), which for the most part has been very good. Two very striking characteristics became evident from the experience with the first package, i.e, not all laboratories are qualified from a staff and equipment point of view, and others lack adequate environmental control to perform measurement at the 0.025 part per million (ppm) level of precision. High levels of precision can be achieved in very poor laboratories, but systematic errors cause large offsets in the results. In summary, the inability to determine air density accurately, very poor laboratory temperature control and low volume, high velocity air flow environmental control systems accounted for most of the non-operator difficulties.

Items of interest addressed to improve the second mass package were automatic computer data acquisition, on-site computer data reduction, accurate instrumentation for measuring the air density parameters of temperature, barometric pressure, and relative humidity, and active temperature control of the artifacts. Changes in the artifacts include the addition a right circular cylinder with a high aspect ratio (height/diameter) for examining surface-dependent thermal effects. 
In general the second circulation of the package was successful but did not completely avoid the difficulties encountered in poor thermal environments. That is, comparing like geometries is inherently more accurate, in a normal laboratory environment, than comparing the unlike geometries like those encountered weighing weight summations. The other noteworthy handicaps encountered were inadequate maintenance of the State kilograms and the absence of precise knowledge of their density. The lack of periodic ties to NIST by some of the participants made calibrations in terms of the State standards pointless. This problem was solved in the third package by including two $1-\mathrm{kg}$ mass standard with an uncertainty on the sum of about $0.06 \mathrm{ppm}$, i.e, 60 micrograms. The importance of a small starting uncertainty at the $1 \mathrm{~kg}$ level is discussed in greater detail later in this paper. We alert the reader at this time that the above uncertainty is relative to the national prototype kilograms $\left(\mathrm{K}_{20}, \mathrm{~K}_{4}\right)$ and does not include any drift in the defining artifact maintained at the BIPM, the so called "grand mass". This aspect of the uncertainty is likewise discussed later.

\section{THE THIRD PACKAGE}

The project had become a resource drain on the NIST mass laboratory staff in that a substantial amount of time was required of us without technical benefits to the Mass Group. After completion of the second package it appeared certain that a complete calibration of a weight set from $1 \mathrm{~kg}$ to 1 mg could easily be accomplished with the NIST mass calibration software, a pair of starting 1 kilogram standards and appropriate check standards. To save time and for the reasons given above, we decided to limit the demonstration to NIST and the State of California. The calibration of the starting kilograms and especially the check standards is very time consuming and entails high cost. Under these circumstances it may have been unwise to proceed with the package. We expended additional labor by including a lap-top computer and wrting a menu-driven version of the NIST mass code. A menu driven code is not only unnecessary but also very inefficient for skilled operators to use and entailed additional and unnecessary labor.

In summary, we provided to the State of California everything required for an "in situ" calibration of their primary mass standard in the range mentioned earlier except for the balances and the skilled operator. California not only provided the balances but a good laboratory environment for their use. Changes to the package for the third round were a better computer, more generalized software, added standards and the elimination of the active weight "soaking" plate and its replacement with a passive plate. Additionally, density measurements were performed on the California kilograms.

\section{HARDWARE and SOFTWARE}

In hardware content, the package remained unchanged in function other than the discontinued use of the active "soaking" plate with the temperature controller. The plate was used without the active electronic circuitry. Other hardware changes did not change the measurement function but improved the operational reliability. The most substantial change was in the computer and software. Any computer that permits the operation of the software and the automatic data acquisition is adequate and it would not be useful to describe it here. However, much effort was expended in developing a documented menu-driven version of the so called "mass code" software. At that juncture we felt it would require less of our time to use a menu structure than to teach others the details of the software. This decision was made before we limited the project to just NIST and the State of California. 
The software itself was developed to limit the options of the statistcal analysis program (mass code) to only the geometric progression of the State standards, 5-3-2-1- $\Sigma 1$. This was acomplished with the menu-controlled software and an editor. The operator is directed through the data collection and analysis, including the report of calibration, and detailed knowlege of the underlying software was not a requirement. Sufficient information for setting up the hardware and initiating the software control of the measurement process was provided in written documentation. The progam gave the operator flexibility in halting and continuing the measurements at junctures not detrimental to the process. Without sufficient computer skills and special knowlege, the operator would not be able to deviate from measurement design. The software did not prevent deviation for those skilled in the measurement and computers, but no information was provided in the documentation on how to proceed.

\section{THE MEASUREMENTS}

The measurement sequence was three complete calibrations performed in Sacramento California and three identical calibrations performed at NIST-Gaithersburg using the same starting kilograms at both locations. These measurements were followed with check measurements of the starting kilograms to ensure a secure tie to the mass unit definition. The set of weights, including the starting standards $T_{1}$ and $T_{2}$, the check standards, and the California set are completely described by the following progression:

$1 \mathrm{~kg} \mathrm{~T}_{1}, 1 \mathrm{~kg} \mathrm{~T}_{2}, 1 \mathrm{~kg} \mathrm{~S}, 1 \mathrm{~kg} \mathrm{~S}_{2}, \Sigma 1 \mathrm{~kg}, 100 \mathrm{~g}$, chk $100 \mathrm{~g}, \Sigma 10 \mathrm{~g}, 10 \mathrm{~g}$, chk $10 \mathrm{~g}, 1 \mathrm{~g}, \Sigma 1 \mathrm{~g}$, chk $1 \mathrm{~g}, 100 \mathrm{mg}, \Sigma 100 \mathrm{mg}$, chk $100 \mathrm{mg}, 10 \mathrm{mg}, \Sigma 10 \mathrm{mg}$, chk $10 \mathrm{mg}, 1_{1} \mathrm{mg}, 1_{2} \mathrm{mg}$, chk $1 \mathrm{mg}$.

In this notation $S_{1}$ and $S_{2}$ are the California state kilograms, the prefix "chk" indicates a check standard supplied by NIST and sum indicates a weight summation with a 5, 3,2 progression. That is, there is a summation of weights for each decade shown, beginning with the sum, $500 \mathrm{~g}+300 \mathrm{~g}$ $+200 \mathrm{~g}$, and ending with the sum, $5 \mathrm{mg}+3 \mathrm{mg}+2 \mathrm{mg}$. Therefore a complete set calibration is accomplished using one series known as "five l's" and repeating a second series, referred to as a "5,3,2,1,1,1", 6 times for a total of seven series. 
The series designs are as follows:

five l's

\section{WEIGHTS}

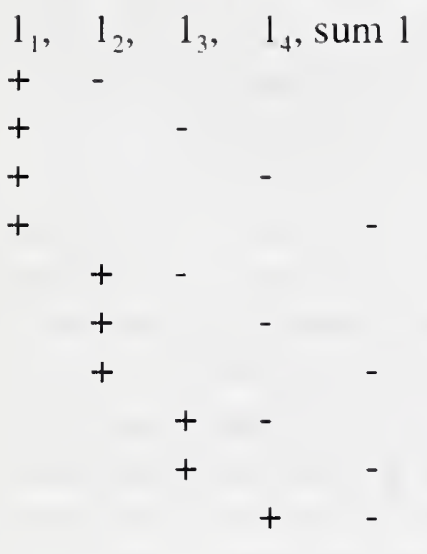

$5,3,2,1,1,1$

\section{WEIGHTS}

$5,3,2,1, \quad$ chk 1 , sum 1

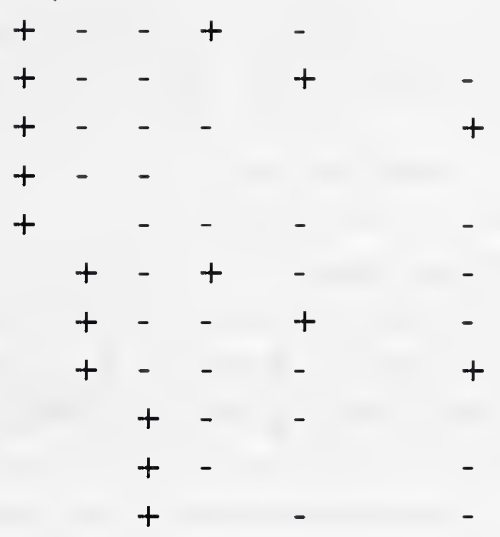

The plus and minus signs in the above designs indicate the force differences to be measured, usually by a balance. Each line of the design gives the weight combinations to be compared i.e. all of the + signs are weights of one load and all of the - signs are weights of the other one. There are various schemes for making the comparisons and in this particular case 4 balances of different capacities are used in an effort to minimize the balance error contribution to the uncertainty assigned by the process. The reader who is unfamiliar with the method will find many fine hours of entertainment by reviewing the literature.

One complete calibration of the weight set requires 76 different weighings and about 7 hours of time in front of the balances. The air density data collection was automatic as were some of the balance observations. Thus, after the last balance observation was taken, the computer provided, via hard copy and magnetic record, a complete data analysis as part of the report of calibration. The time required for a complete calibration is initially somewhat longer as many pieces of data must be entered into the computer. Additional time is allotted after moving the weights between the balances to acquire thermal equilibrium. The process cannot be shortened without great risk of increaing the magnitude of systematic errors. As mentioned earlier, three complete calibrations of the weight set were performed by each participant and therefore one can expect to take statistical advantage of the multiple values in assigning the final uncertainties. The data was accumulated in a deliberate fashion, i.e., completing a full set calibration before beginning another. This format permits all of the random effects that one may not perceive to influence the measurement process. These effects, if any, are then more apt to be observable, i.e., between-time-components. Table 1 presents the mass assignments to each weight in the set for all six calibrations.

\section{DATA}

First, there is nothing remarkable about the data given in Table 1. The results were expected based upon the many years of experience the NIST mass group has had with round robins since the early 1960 's. Our awareness of the all around excellence to be found in the California laboratory guaranteed the results would be comparable to a routine calibration performed by NIST. However, 
Table 2 presents the more noteworthy statistics that are routinely generated by the fine statistical program written by Varner [7]. The program is the result of a very large effort undertaken jointly by the Mass Group and the statistical laboratory at NIST during most of the 1960s. These studies [8] are the underpinning of the mass calibration program still in use today. The software used here is merely a menu driven version of that so-called "mass code" written specifically for these measurements and for operators with limited computer knowlege. There are many calculations made by the analysis program but a key few are sufficeint to judge adequacy of the assigned mass values. They are the statistical f-test and t-test, which are given in Table 2 for all of the series.

A brief description of data reduction and analysis is given here for the reader who is not familiar with the process. If one reviews the two measurement designs we described earlier a few cardinal features will be observed. First, all mass values arise from the two starting standards, kilograms $T_{1}$ and $\mathrm{T}_{2}$. Secondly, all possible weight combinations are observed on the balance for the five 1's series while this is not true for the 5-3-2-1-1-1 series. However, both series have the common property of being over-determined. That is there is more information available than is really necessary for a simple mass assignment. This last feature allows us to apply the statistical test that we discuss here. Finally, the calibration is a chain of measurements where each series is linked together by the value of mass assigned to summation in the decade above. In conclusion, the series is a sequence of force differences observed on a balance that is proportional to the gravitational forces imposed by the mass and its displacement volume when weighed in air. When corrected for buoyancy the system of equations can be solved for the masses involved and utilize the method known as "least squares" to take advantage of the additional information, as there are more observations than are necessary for a solution.

This weighing method consumes considerably more time than the simple "one on one" measurement but provides the statistics needed to ensure the calibration is free of major errors, and provides the information needed to assign realistic estimates of uncertainty to the assigned mass values. 
(1) 이

䨔

E.

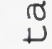

- $\Omega$

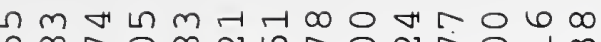

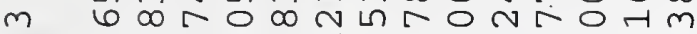
त 4 तथ

H $600 \mathrm{~L} 06 \mathrm{~N} N \mathrm{~N}$ m N N N L ब $\infty$ N $\circ 0000$ \% 000000 \% o o o o a o o o o o o a

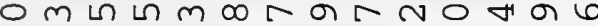
mol

N a $N$ a

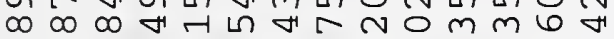

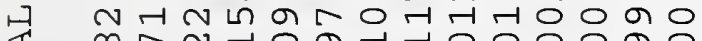

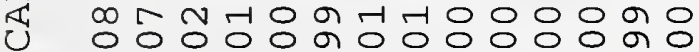

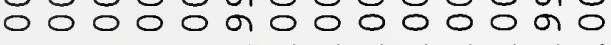

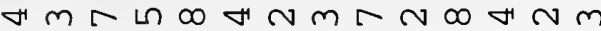

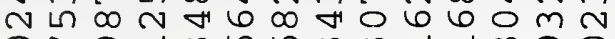

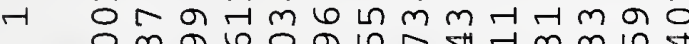
Om 6 o mNN DN N 00000 a 000000 a 0 00000 a 000000 a

ก

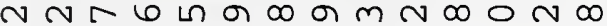

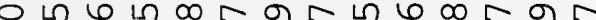
$\infty 6606$ \% $\mathrm{N} 6 \mathrm{~N} 0 \mathrm{~N} \mathrm{~m} \mathrm{~m}$ न $\infty \pi$ ก 00000 a 00000000 o o o o a 000000 a

$\sim$

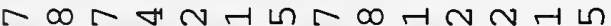
$6 m \sim 6$ \%

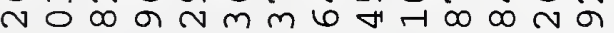

E $N R$ H

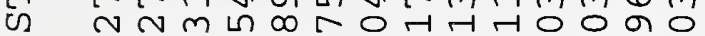

桨 0 \%

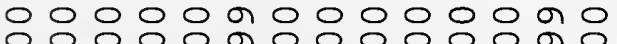
o o o o a o o o o o o a

HL $\infty$ H - 6 H 6 \% Hनr

$-1$

in

骂 $00 \sim 006 \mathrm{~m} 00 \mathrm{~mm} 6 \mathrm{H}$ N N N I D N $\infty \pi$ त

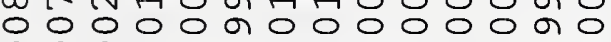
0000000000000

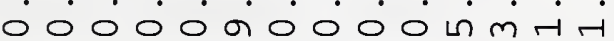
00000 \% 00 in $N$

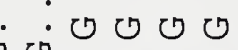

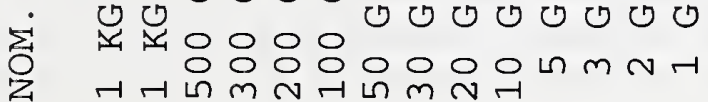
オひひ

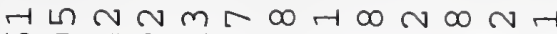
60 म - O बח $\mathrm{N}$ त

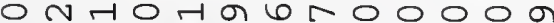
00000 a $\sigma 0000$ a 00000 月 $\ln \mathrm{m} N \mathrm{H}$ $0 \mathrm{O} O \mathrm{O} N \mathrm{~N}$ H 00000 n m N

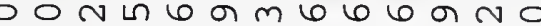
त न म

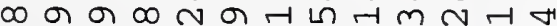
0 न $10 \pi \infty 6 \pi 00000$ 00000 a $/ 0000$ 月

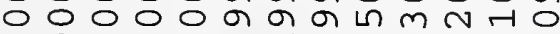
$0000 \mathrm{n}$ N InNAOO

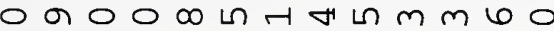

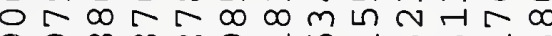

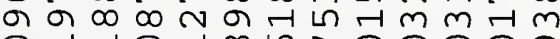

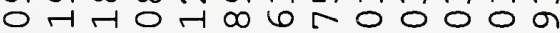
○ 000 a $\sigma 0000$ \%

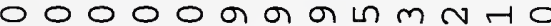
0000 n n H 00000 L m n

HR $m+6$ H $\infty \pi \circ m \sim r \infty \sim m \sim \infty$

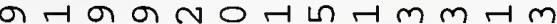

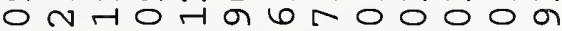
00000 न $0^{\circ} 0000$ \% 00000 \% 0000 L N

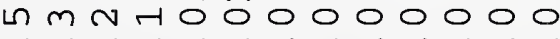

$\infty$ L

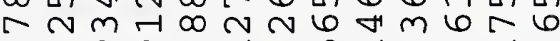

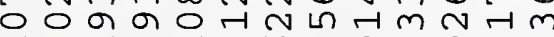
न ○ 000 a a a 0000 a

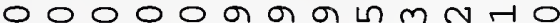

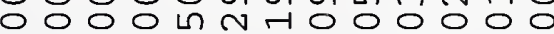
n m n t 00000000

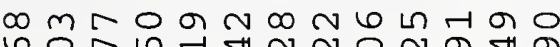

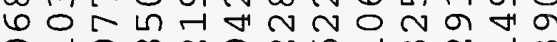

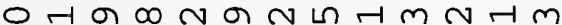
न त ○ 000 a 0 a 0000 a

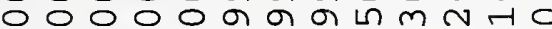
o 000 n N H 000000 L m N

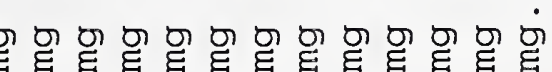
$00000000 \mathrm{mNH}$ $0000 \mathrm{~m} N$ in $m \rightarrow$
छ

त 4

$0 \cdot-4$

म

प्र

-

हี

4.

a 0

近 7

둥

10

ฮี

$\perp$

U

ט

U

ฮั

व

-

¿ 0

너음

4

-4

त。

บ 0

(1) 兵

㝳 岂

4

(1) 4

เ

○

द $\stackrel{0}{0}$

- 3

\% 2

प्र

- -4 U

ते

0 i 0

(4)으뭉

एव

0 U

- (1)

-1)

(1) 그

ते हू.

E U Y 



\section{ANALYSIS}

The software (mass code) serves two primary functions in that it reduces the raw data to mass values and computes an associated uncertainty based on input parameters. A third function is quality control. This is accomplished by comparing present balance peformance and check standard values to thier historical values (t-test and F-test). These values are used by the operators as "go" and "nogo" criteria, i.e., values within the prescribed limits are indicative of a process with predictable behavior. The limits used here are that the F- test value must be less than 2.81 and the absolute value of $t$ less than 3. The selection of the limits and the details of the test can be found in the literature [8]. Table 2 gives the values computed for the NIST measurements and those of California, all are within the limits. The reader should note that California used different balances and check standards than NIST except for the $1-\mathrm{kg}$ level. Table 3 presents the starting kilogram check $\left(\mathrm{T}_{1}-\mathrm{T}_{2}\right)$ data in a more interesting format. That is, the accepted value and the observed value are given for each measurement. Except for the starting check $\left(T_{1}-T_{2}\right)$ the check standards provided to California are not the same as those used at NIST and were assigned mass values on the basis of six mass determinations each as opposed to hundreds at NIST. More work in assigning mass values to the check standards would not be cost effective. Beyond the t-test values already discussed, there is nothing to be gained in further analyzing the data.

It is instructive to look at the mean mass values for each weight in the set by location. Table 4 presents the mean value for each location, the difference in the mean value and the corresponding standard deviation. To make a judgment as to the adequacy of the assigned mass values, one must know their uncertainty and then judge in terms of the expected application. The second part of this postulate is answered on the basis of need. One must be able to compare their uncertainties with those required by specific application.

From experience we know there are always users of the measurement system who want to improve on the basis of ego and not real need. That is, these users desire to be on par with NIST regardless of the economic cost or usefulness. There are real limits to need imposed by characteristics of the equipment ancillary to each application. For example, piston gage weights need not be much better than 10 parts per million (ppm). Many gravimetric applications are in the range between $100 \mathrm{ppm}$ $1 \mathrm{ppm}$, such as volumetric calibration and the density of solids and liquids. In fact, there are few requirements below $1 \mathrm{ppm}$ other than these scientific applications. Most mass measurements are directed towards compliance to weight adjustment tolerences such as those set forth by ASTM, OIML, or balance calibration requirements. Except for the very uncommon weight classes that are only achievable by a state-of-practice calibration, almost all of these tolerences range from $5 \mathrm{ppm}$ to $500 \mathrm{ppm}$. Probably the largest industrial application is the certification of balances, and here again the limits are similar to those of weights. Of course, as balances improve, the calibration requirements will be more demanding and will reqiure mass standards with very small uncertainties. If surrogate laboratories are able to meet the uncertainty requirement, and the demand develops, then the work decribed here may be useful.

The uncertainty of the mass of a standard is determined from the random and systematic errors associated with the measurement process, type A and type B errors respectively. Some of these errors are readily determined and others are not. For instance, the correction of the thermometer used to measure air temperature is attainable through calibration. However, the application of the thermometer to the measurement process may be incorrect or not understood, leading to a 
temperature error. The latter situation may be unknown to those directly involved and the true uncertainty unknown. Through careful analysis and long term effort the performance of a measurement process may become fairly well known. Then one appeals to an accepted statistical method for calculating the measurement uncertainty. This uncertainty in the case of a routine NIST mass determination means that the artifact behavior is assumed to be similar to the NIST check standards that are constantly being recalibrated; therefore, one can assign a reasonable estimate of uncertainty based on a single calibration of a client's artifact. In a sense, these artifacts are fragile and it is very difficult, without the proper facilities and techniques, to acertain the on-going validity of an assigned mass value. The statement of uncertainty does not reveal any information regarding the use of the artifact in another measurement process other than that it becomes a source of type B error when used as the standard.

The uncertainty assigned to each of the California State weights based on a single calibration is given in Table 5. We have given the uncertainty based on the newly adopted ISO recommendation along with the uncertainty as calculated presently. In essence, the new method adds the type A and $B$ errors in quadrature and multiplies the result by two for a $95 \%$ confidence level, and the old method is $3 \mathrm{~A}+\mathrm{B}$ for a $99 \%$ confidence level. Type A errors arise from the measurement process, random error, and type $B$ from systematic errors. Since weighing designs are used in the calibration process, the detail may be obscured. However, in terms of the starting kilograms, $T_{1}$ and $T_{2}$ the uncertainty of the work performed in California is comparable to the NIST calibrations. If the integraty of the starting standards is ensured, then all is well. We note that the average check values of these standards, for both locations indicate a shift of about 20 micrograms. This offset between the excepted and observed values is not alarming but does merit their recalibration.

\section{CONCLUSIONS}

We conclude from this exercise that the California State laboratory is on par with a routine NIST calibration when using the standards and methods described here. However, the method does illustrate the critical dependence on the integrity of the starting kilogram standards. To achieve the uncertainties stated here requires a state-of-the-art calibration of the starting kilogram standards, and probably a rigorous monitoring program thereafter. Otherwise, through wear and tear these fragile artifacts will introduce systematic errors in the calibration process. Some significant errors can remain undetected for some time.

The reader can get some idea of the system stabilty by comparing prior calibrations of the California weights to the present ones. We have adjusted the former calibrations of the California weights to compensate for the 1990 mass scale shift and compare the values to average of all six measurments of this work in Table 5. Considering the 26-year time span and an even longer period of inattention given to the NIST working standards the system is quite stable. One can only conclude that the State of California has treated the kilograms with care.

The implementation of a surrogate laboratory program would entail an expensive effort to maintain and track the starting kilogram pairs. In addition, tracking of the entire measurement process to assure that the uncertainty statements have validity would be a requirement. NIST management may not wish to validate calibrations not directly under their control. 
The method of the circulating package if properly designed and managed would fill an obvious training gap that exists at near state-of-the- art mass measurement in the country today. Futhermore, the examination of laboratories for certification at this high level of accuracy would require the kind of laboratory examination techniques developed as part of this program.

\begin{tabular}{||l|l|c|c|c|c|c||}
\hline \multirow{2}{*}{ series } & \multicolumn{2}{|c|}{ run } & \multicolumn{2}{c|}{ run 2 } & \multicolumn{2}{c|}{ run 3 } \\
\cline { 2 - 8 } & $\mathrm{F}$ & $\mathrm{T}$ & \multicolumn{1}{c|}{$\mathrm{F}$} & $\mathrm{T}$ & $\mathrm{F}$ & $\mathrm{T}$ \\
\hline 1 & 1.531 & 0.65 & 1.309 & 0.041 & 0.763 & 1.59 \\
\hline 2 & 0.520 & -2.54 & 2.046 & -0.41 & 2.661 & -1.33 \\
\hline 3 & 0.396 & -0.46 & 0.778 & -0.61 & 1.069 & -1.38 \\
\hline 3 & 2.807 & 0.17 & 1.894 & -0.39 & 0.760 & 1.09 \\
\hline 5 & 1.286 & 1.92 & 0.449 & -2.33 & 0.848 & 0.90 \\
\hline 6 & 1.080 & -1.11 & 2.177 & -2.44 & 1.701 & -1.49 \\
\hline 7 & 0.760 & -1.57 & 0.404 & -0.66 & 0.347 & -1.49 \\
\hline & \multicolumn{7}{|c|}{ California } & & \\
\hline 1 & 0.606 & 0.91 & 0.568 & 0.57 & 1.224 & 0.75 \\
\hline 2 & 1.033 & 1.04 & 0.187 & 1.76 & 1.423 & 0.48 \\
\hline 3 & 0.717 & -1.88 & 0.530 & 1.68 & 2.785 & 1.12 \\
\hline 3 & 2.475 & -1.35 & 2.581 & 0.52 & 2.727 & 0.33 \\
\hline 5 & 0.897 & 1.22 & 1.422 & -1.28 & 1.958 & 1.41 \\
\hline 6 & 0.365 & 0.54 & 1.796 & 0.48 & 0.321 & 2.18 \\
\hline 7 & 2.199 & -1.94 & 0.866 & -2.78 & 0.566 & -2.80 \\
\hline \hline
\end{tabular}

Table 2. F and t test values for all six calibrations. All values are within the prescribed limits. 


\begin{tabular}{||l|l|l|l|l|l|}
\hline \hline \multicolumn{7}{|c|}{ ACCEPTED VALUE $T_{1}-\mathrm{T}_{2}=1.149 \mathrm{mg}$} \\
\hline CA 1 & CA 2 & CA 3 & NIST 1 & NIST 2 & NIST 3 \\
\hline 1.177 & 1.167 & 1.173 & 1.167 & 1.160 & 1.192 \\
\hline \multicolumn{4}{|c|}{ AVERAGE $=1.173 \mathrm{mg}$} \\
\hline
\end{tabular}

Table 3. The starting kilogram check values determined by the measurements at both locations.

\begin{tabular}{|c|c|c|c|c|}
\hline $\begin{array}{l}\text { Nominal } \\
\text { Mass }\end{array}$ & $\begin{array}{c}\text { NIST Mean } \\
\text { Corr. mg }\end{array}$ & $\begin{array}{c}\text { CA Mean Corr. } \\
\text { mg }\end{array}$ & $\begin{array}{c}\text { Type A Error } \\
\text { mg }\end{array}$ & $\begin{array}{l}\text { Difference } \\
\text { NIST - CA } \\
\end{array}$ \\
\hline $1 \mathrm{~kg}$. & 8.219 & 8.286 & 0.025 & -0.067 \\
\hline $1 \mathrm{~kg}$. & 7.212 & 7.212 & 0.025 & 0 \\
\hline $500 \mathrm{~g}$ & 2.288 & 2.289 & 0.016 & -0.001 \\
\hline 300 & 1.521 & 1.555 & 0.040 & -0.034 \\
\hline 200 & 0.881 & 0.908 & 0.012 & -0.027 \\
\hline 100 & -0.227 & -0.229 & 0.015 & -0.002 \\
\hline 50 & 1.035 & ๑. 041 & 0.008 & -0.006 \\
\hline 30 & 1.173 & 1.174 & 0.008 & -0.001 \\
\hline 20 & 0.123 & 0.130 & 0.0115 & -0.007 \\
\hline 10 & 0.106 & 0.110 & 0.006 & -0.004 \\
\hline 5 & 0.038 & 0.033 & 0.003 & 0.001 \\
\hline 3 & 0.038 & 0.034 & 0.002 & 0.004 \\
\hline 2 & -0.038 & 0.0197 & 0.381 & -0.002 \\
\hline 1 & 0.040 & 0.041 & 0.0 & -0.004 \\
\hline $500 \mathrm{mg}$ & 0.0104 & 0.0082 & 0.0004 & 0.0022 \\
\hline 300 & 0.0003 & 0.0197 & 0.0003 & 0.0011 \\
\hline 200 & 0.0194 & 0.0192 & 0.0003 & 0.0022 \\
\hline 100 & $0.000 \mathrm{~B}$ & 0.0084 & 0.0002 & 0.0006 \\
\hline 50 & 0.0118 & 0.0125 & 0.0002 & -0.0007 \\
\hline 30 & -0.0097 & -0.0100 & 0.0001 & -0.0003 \\
\hline 20 & -0.0379 & -0.0382 & 0.0001 & -0.0003 \\
\hline
\end{tabular}




\begin{tabular}{||c|c|c|c|c||}
\hline 10 & -0.0246 & -0.0248 & 0.0001 & -0.0002 \\
\hline 5 & 0.0012 & 0.0015 & 0.0001 & -0.0003 \\
\hline 3 & 0.0033 & 0.0034 & 0.0001 & -0.0001 \\
\hline 2 & 0.0029 & 0.0030 & 0.0001 & -0.0001 \\
\hline 1 & 0.0015 & 0.0018 & 0.0001 & -0.0003 \\
\hline 1. & -0.0062 & -0.0061 & 0.0001 & 0.0001 \\
\hline
\end{tabular}

Table 4. Shown here are the differences in milligrams between the mean values assigned at NIST and California. The type "A" error is identical for both laboratories but does not include a between-time component.

\begin{tabular}{||l|l|l|l|l|l||}
\hline $\begin{array}{c}\text { NOMINAL } \\
\text { VALUE }\end{array}$ & $\begin{array}{c}\text { MASS 67 } \\
\text { ADJ TO 90 }\end{array}$ & \multicolumn{1}{|c|}{$\begin{array}{c}\text { MASS } \\
\text { AVERAGE 92 }\end{array}$} & \multicolumn{1}{c|}{ DIFF.g } & $\begin{array}{c}\text { UNC. g } \\
93\end{array}$ & $\begin{array}{c}\text { POST g } \\
1993\end{array}$ \\
\hline $1 \mathrm{~kg}$. & 1000.008249 & 1000.008253 & -.000004 & $.0000 \AA 7$ & .000043 \\
\hline $1 \mathrm{~kg}$. & 1000.007185 & 1000.007211 & -.000026 & .000087 & .000043 \\
\hline $500 \mathrm{G}$ & 500.002749 & 500.002288 & .000461 & .000047 & .000024 \\
\hline $300 \mathrm{G}$ & 300.001629 & 300.001538 & .000091 & .000034 & .000018 \\
\hline $200 \mathrm{G}$ & 200.000959 & 200.000895 & .000009 & .000025 & .000014 \\
\hline $100 \mathrm{G}$ & 99.999950 & 99.999772 & .000178 & .000025 & .000015 \\
\hline $50 \mathrm{G}$ & 50.001065 & 50.001038 & .000027 & .000014 & .000008 \\
\hline $30 \mathrm{G}$ & 30.001181 & 30.001173 & .000009 & .000010 & .000006 \\
\hline $20 \mathrm{G}$ & 20.000170 & 20.000126 & .000044 & .000008 & .000005 \\
\hline $10 \mathrm{G}$ & 10.000117 & 10.000108 & .000009 & .000008 & .000005 \\
\hline $5 \mathrm{G}$ & 5.000049 & 5.000034 & .000015 & .000004 & .000063 \\
\hline $3 \mathrm{G}$ & 3.000041 & 3.000036 & .000005 & .000003 & .000002 \\
\hline $2 \mathrm{G}$ & 1.999966 & 1.999961 & .000005 & .000002 & .000002 \\
\hline $1 \mathrm{G}$ & 1.000043 & 1.000040 & .000003 & .000003 & .000002 \\
\hline \hline
\end{tabular}

Table 5. See Text for Explanation.

\section{REFERNCES}

\{1\} Schoonover, R.M., "Advance Mass Calibration in State Laboratories," NBSIR 83-2752 (1983).

\{2\} Schoonover, R.M. , "Some Recent Developments at NBS in Mass Measurements," IEEE Insturmentation and Measurement Technology Conference, Boulder, CO (1986). 
\{3\} Schoonover, R.M.; Taylor, J.E., "An Investigation of a User-operated Mass Calibration Package," NISTIR 88-3876 (1988)

\{4\} Schoonover, R.M.; Davis, R.S.; Driver, R.G.; Bower, V.E., "A Practical Test of the Air Density Equation in Standards Laboratories at Differing Altitude," J. Res. NBS 85: 27-38 (1980).

\{5\} Schoonover, R.M.: Keller, J., "A Surface-Dependent Thermal Effect in Mass Calibration and What You Can Do About It," Proc. 68th National Conference on Weights and Measures, Sacramento, CA (1983).

\{6\} Glaser, M., "Response of Apparent Mass to Thermal Gradients," Metrologia 27, 95-100 (1990)

\{7\} Varner, R.N.; Raybold, R.C., "National Bureau of Standards Mass Calibration Computer Software," NBS Technical Note 1127 (1980)

\{8\} Pontius, P.E., "Notes on the Fundamentals of Measurement and Measurement as a Production Process," NBSIR 74-545 (1974) 

